\title{
Reference curves for BMI, waist circumference and waist-to-height ratio for Azorean adolescents (Portugal)
}

\author{
Rute Santos ${ }^{1, *}$, Carla Moreira ${ }^{1}$, Jonatan R Ruiz ${ }^{2,3}$, Susana Vale 1 , Luisa Soares-Miranda ${ }^{1}$, \\ Pedro Moreira ${ }^{1,4}$, Luis Lopes ${ }^{5}$, Ana I Marques ${ }^{1}$, Antonio Oliveira-Tavares ${ }^{1}$, \\ Paula C Santos ${ }^{1,6}$, Sandra Abreu ${ }^{1}$, Manuel J Coelho-Silva ${ }^{7}$ and Jorge Mota ${ }^{1}$ \\ ${ }^{1}$ Research Centre in Physical Activity, Health and Leisure, Faculty of Sport, University of Porto, Rua Dr. Plácido \\ Costa 91, 4200-450 Porto, Portugal: ${ }^{2}$ Department of Physical Education and Sport, School of Physical Activity \\ and Sport Sciences, University of Granada, Carretera de Alfacar, Granada, Spain: ${ }^{3}$ Unit for Preventive \\ Nutrition, Department of Biosciences and Nutrition at NOVUM, Karolinska Institutet, Huddinge, Sweden: \\ ${ }^{4}$ Faculty of Nutrition, University of Porto, Porto, Portugal: ${ }^{5}$ Campus de Gualtar, Institute of Education (CIEC), \\ Minho University, Braga, Portugal: 'Department of Physical Therapy, School of Health Technology of Porto, \\ Polytechnic Institute of Porto, Vila Nova de Gaia, Portugal: ${ }^{7}$ Research Center for Sport and Physical Activity, \\ Faculty of Sport Sciences and Physical Education, University of Coimbra, Coimbra, Portugal
}

Submitted 3 January 2010: Accepted 29 July 2011: First published online 7 September 2011

\begin{abstract}
Objective: There are no percentile curves for BMI, waist circumference (WC) or waist-to-height ratio (WHtR) available for Portuguese children and adolescents. The purpose of the present study was to develop age- and sex-specific BMI, WC and WHtR percentile curves for a representative sample of adolescents living in the Portuguese islands of Azores, one of the poorest regions of Europe, and to compare them with those from other countries.

Design: Cross-sectional school-based study. Weight, height and WC were objectively measured according to standard procedures. Smoothed percentile curves were estimated using Cole's LMS method.

Setting: Azores, Portugal.

Subjects: Proportionate stratified random sample of 1500 adolescents, aged 15-18 years.

Results: Results showed some sex differences in the shape of the BMI curves: in girls, the upper percentile values tend to decrease by the age of 16 and 17 years; whereas in boys, the upper percentiles tend to be flat between 15 and 16 years and then increase until the age of 18 years. In both sexes, the upper percentile values of both WC and WHtR decreased slightly by the age of 16 years and then increased steeply. In both sexes, the Azorean values for the 50th and 90th WC percentiles were higher than those reported for adolescents from the majority of other countries.

Conclusions: The reference curves presented herein provide baseline data for the long-term surveillance of Azorean adolescents, as well as for national and international comparisons.
\end{abstract}

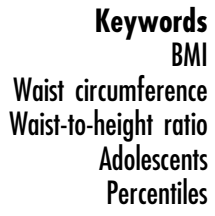

Childhood and adolescent obesity has become an important public health problem, as its prevalence has increased significantly over the past years in several countries ${ }^{(1)}$. In Portugal, about a third of children and adolescents are overweight or obese ${ }^{(2)}$.

There are some sophisticated methods to accurately measure body fat, such as computed axial tomography or dual-energy X-ray absorptiometric densitometry; however, such techniques are not feasible to apply in large epidemiological studies or even in clinical settings because they are complex, time consuming and expensive. Therefore, several anthropometric measures and indices have been proposed for screening overweight and obesity.

The BMI, an indicator of general adiposity, has been commonly used to identify overweight and obese children and adolescents. BMI is an index (weight/height ${ }^{2}$ ) that is simple to measure and is a valuable tool to monitor trends in obesity prevalence. Therefore, the Centers for Disease Control $^{(3)}$, the International Obesity Taskforce ${ }^{(4)}$ and $\mathrm{WHO}^{(5)}$ have developed sex- and age-specific BMI cut-off values for children and adolescents. However, BMI is a suboptimal marker of body fat because it does not 
distinguish fat from lean tissue or bone, and therefore classifying people as overweight or obese based on their BMI may lead to significant misclassification. Moreover, BMI is not a suitable method to assess body fat distribution ${ }^{(6)}$ and it has been suggested that BMI may be a less sensitive indicator of fat in children and adolescents than waist circumference (WC) or waist-to-height ratio (WHtR) ${ }^{(6,7)}$.

Abdominal obesity seems to reflect intra-abdominal fat, including visceral adipose tissue ${ }^{(8-10)}$, and it is known that increased visceral adipose tissue is strongly correlated with CVD risk factors ${ }^{(11)}$. During childhood and adolescence, it is known that abdominal obesity is an important predictor for several CVD risk factors ${ }^{(12-15)}$; therefore it is considered a critical component of the paediatric metabolic syndrome definition proposed by the International Diabetes Federation $^{(16)}$.

WC is a simple, effective and inexpensive anthropometric tool to measure abdominal adiposity and related metabolic risks in children of different ethnicities ${ }^{(6,17-21)}$. For children and adolescents, there are no internationally accepted cut-off values; however, WC centile charts have been developed for children and adolescents in some countries $^{(22-36)}$.

WHtR has been proposed as a convenient alternative measurement to assess central fatness in children ${ }^{(13)}$. Similar to WC, WHtR has been shown to be strongly correlated with abdominal fat measured using imaging techniques ${ }^{(11,37)}$. Correcting WC to height may obviate the need for age-, sexand ethnic-related reference values ${ }^{(38)}$, while WC requires population-specific cut-off values ${ }^{(39)}$. Recently, in a systematic review, Browning et al. ${ }^{(40)}$ showed that the area under the curve in a receiver-operating curve analysis provides good evidence that a WHtR of 0.5 is a good boundary value for men and women across many ethnic groups. However, some studies are required in order to understand if WHtR may allow the same boundary values for children and adults in different ethnic groups.

Centile reference charts are commonly used in paediatrics and are useful to understand how a child's parameter can be compared with the expected parameters of children of the same age and sex in order to determine whether the child is growing appropriately. To the best of our knowledge, there are no references charts for BMI, WC and WHtR for adolescents living in the Portuguese Archipelago of Azores with which to monitor obesity trends or assess abdominal obesity. Therefore, the purpose of the present study was to develop age- and sex-specific BMI, WC and WHtR percentile curves for Azorean adolescents aged 15-18 years, and to compare them with those from other countries.

\section{Methods}

\section{Study design and sampling}

Data for the present study were derived from a schoolbased study, the Azorean Physical Activity and Health
Study II (APAHS II), which aimed to examine the relationships between physical activity, physical fitness, overweight/obesity prevalence, health-related quality of life and other factors. The study was carried out in six of the nine Azorean Islands, where $95 \%$ of the population lives: São Miguel, Terceira, Faial, Pico, São Jorge and Graciosa ${ }^{(41)}$.

The sample was selected by means of a proportionate stratified random sampling, taking into account the location (island) and the number of students, by age and sex, in each school. Schools were randomly selected within each island until the established number of students by island was attained. All selected schools participated in the study. The established number of students was 1422, but the sample was oversized in order to prevent loss of information and because, technically, it was necessary to do the fieldwork in complete classrooms. Therefore, data were collected for 1525 adolescents aged 15-18 years.

Twenty-five students aged $<14.5$ or $>18.4$ years, and/or having a health condition that did not allow for participation in physical education classes, and/or having missing information on the variables of interest were excluded, resulting in a total of 1500 participants (892 girls and 698 boys). Finally, the sample was adjusted by a weight factor in order to balance the sample in accordance to the distribution of the Azorean population in the schools and to guarantee the real representativeness of each of the groups (age and sex).

All participants were informed about the objectives of the study and parents or guardians of each participant provided written informed consent. The study was approved by the Faculty and the Portuguese Foundation for Science and Technology ethics committees, and was conducted in accordance to the Declaration of Helsinki for Human Studies of the World Medical Association ${ }^{(42)}$.

Measurements took place during autumn 2008. Participants were evaluated during school physical education classes by physical education teachers specially trained for the data collection.

\section{Measures}

Body height, body weight and waist circumference

Body height was measured to the nearest millimeter in bare or stocking feet with the adolescent standing upright against a stadiometer (Holtain Ltd, Crymych, UK). Body weight was measured to the nearest $0 \cdot 10 \mathrm{~kg}$, with the adolescent lightly dressed and without shoes, using a portable electronic weight scale (model Inner Scan BC 532; Tanita, Tokyo, Japan). BMI was calculated as weight divided by the square of height $\left(\mathrm{kg} / \mathrm{m}^{2}\right)$.

WC was measured twice, with a non-elastic metal anthropometric tape, midway between the lower rib margin and the iliac crest at the end of normal expiration ${ }^{(43)}$ and the average of the two measures was used for analysis. If the two measurements differed by $>1 \mathrm{~cm}$, a third measurement was taken and the two closest measurements were averaged.

WHtR was calculated as the ratio WC $(\mathrm{cm}) /$ height $(\mathrm{cm})$. 
Table 1 Sample size for weight, height, BMI, waist circumference (WC) and waist-to-height ratio (WHtR), by sex and age, among a proportionate stratified random sample of 1500 adolescents, aged 15-18 years, Azores, Portugal

\begin{tabular}{|c|c|c|c|c|c|c|c|c|c|c|c|c|}
\hline \multirow[b]{2}{*}{ Sex } & \multirow[b]{2}{*}{ Age (years) } & \multirow[b]{2}{*}{$n$} & \multicolumn{2}{|c|}{ Weight $(\mathrm{kg})$} & \multicolumn{2}{|c|}{ Height $(\mathrm{cm})$} & \multicolumn{2}{|c|}{ BMI $\left(\mathrm{kg} / \mathrm{m}^{2}\right)$} & \multicolumn{2}{|c|}{ WC (cm) } & \multicolumn{2}{|c|}{ WHtR } \\
\hline & & & Mean & SD & Mean & SD & Mean & SD & Mean & SD & Mean & SD \\
\hline Girls & $\begin{array}{l}15 \\
16 \\
17 \\
18\end{array}$ & $\begin{array}{r}289 \\
264 \\
258 \\
81\end{array}$ & $\begin{array}{l}58 \cdot 28 \\
57 \cdot 91 \\
59 \cdot 17 \\
61 \cdot 01\end{array}$ & $\begin{array}{r}11 \cdot 45 \\
9 \cdot 83 \\
10 \cdot 33 \\
11 \cdot 11\end{array}$ & $\begin{array}{c}159 \cdot 7 \\
159 \cdot 9 \\
161 \cdot 1 \\
160 \cdot 1\end{array}$ & $\begin{array}{l}5 \cdot 91 \\
6 \cdot 12 \\
6 \cdot 78 \\
6 \cdot 15\end{array}$ & $\begin{array}{l}22 \cdot 79 \\
22 \cdot 61 \\
22 \cdot 78 \\
23 \cdot 78\end{array}$ & $\begin{array}{l}3.93 \\
3.42 \\
3.49 \\
4.00\end{array}$ & $\begin{array}{l}79 \cdot 05 \\
77 \cdot 63 \\
80 \cdot 24 \\
82 \cdot 75\end{array}$ & $\begin{array}{r}10 \cdot 18 \\
9 \cdot 98 \\
9 \cdot 66 \\
10 \cdot 92\end{array}$ & $\begin{array}{l}0.49 \\
0.49 \\
0.50 \\
0.52\end{array}$ & $\begin{array}{l}0.06 \\
0.06 \\
0.06 \\
0.07\end{array}$ \\
\hline Boys & $\begin{array}{l}15 \\
16 \\
17 \\
18\end{array}$ & $\begin{array}{r}200 \\
185 \\
160 \\
63\end{array}$ & $\begin{array}{l}64 \cdot 41 \\
67 \cdot 96 \\
70 \cdot 54 \\
71 \cdot 28\end{array}$ & $\begin{array}{l}13 \cdot 57 \\
12 \cdot 57 \\
14 \cdot 29 \\
12 \cdot 56\end{array}$ & $\begin{array}{l}168 \cdot 9 \\
173 \cdot 1 \\
172 \cdot 5 \\
173 \cdot 9\end{array}$ & $\begin{array}{l}7 \cdot 32 \\
6 \cdot 66 \\
6 \cdot 27 \\
5 \cdot 48\end{array}$ & $\begin{array}{l}22 \cdot 52 \\
22 \cdot 68 \\
23 \cdot 68 \\
23 \cdot 54\end{array}$ & $\begin{array}{l}4 \cdot 18 \\
3 \cdot 99 \\
4 \cdot 50 \\
4 \cdot 05\end{array}$ & $\begin{array}{l}78 \cdot 70 \\
79 \cdot 88 \\
81 \cdot 45 \\
83 \cdot 12\end{array}$ & $\begin{array}{l}10 \cdot 97 \\
10 \cdot 20 \\
11 \cdot 21 \\
10 \cdot 36\end{array}$ & $\begin{array}{l}0.47 \\
0.46 \\
0.47 \\
0.48\end{array}$ & $\begin{array}{l}0.06 \\
0.06 \\
0.07 \\
0.06\end{array}$ \\
\hline Total & & 1500 & & & & & & & & & & \\
\hline
\end{tabular}

Table 2 Smoothed age- and sex-specific percentile values for weight, height, BMI, waist circumference (WC) and waist-to-height ratio $(\mathrm{WHtR})$, by sex and age, among a proportionate stratified random sample of 1500 adolescents, aged 15-18 years, Azores, Portugal

\begin{tabular}{|c|c|c|c|c|c|c|c|c|c|}
\hline \multirow[b]{2}{*}{ Measure } & \multirow[b]{2}{*}{ Sex } & \multirow[b]{2}{*}{ Age (years) } & \multicolumn{7}{|c|}{ Percentile } \\
\hline & & & 5 th & 10th & 25th & 50th & 75th & 90th & 95th \\
\hline \multirow[t]{8}{*}{ Weight (kg) } & Girls & 15 & $43 \cdot 0$ & $46 \cdot 0$ & $49 \cdot 8$ & 56.5 & 63.3 & $74 \cdot 1$ & $80 \cdot 4$ \\
\hline & & 16 & $43 \cdot 7$ & $47 \cdot 1$ & $50 \cdot 9$ & $57 \cdot 0$ & $63 \cdot 2$ & $71 \cdot 5$ & $79 \cdot 4$ \\
\hline & & 17 & $45 \cdot 5$ & $48 \cdot 4$ & $52 \cdot 1$ & 57.0 & $64 \cdot 3$ & $71 \cdot 7$ & $78 \cdot 0$ \\
\hline & & 18 & $45 \cdot 0$ & $47 \cdot 9$ & $51 \cdot 9$ & $59 \cdot 6$ & $69 \cdot 3$ & $75 \cdot 9$ & $80 \cdot 9$ \\
\hline & Boys & 15 & $47 \cdot 1$ & $49 \cdot 7$ & $55 \cdot 5$ & $62 \cdot 1$ & $71 \cdot 1$ & $83 \cdot 5$ & $93 \cdot 1$ \\
\hline & & 16 & $51 \cdot 9$ & $54 \cdot 3$ & $58 \cdot 9$ & $65 \cdot 8$ & $74 \cdot 7$ & $85 \cdot 3$ & $92 \cdot 6$ \\
\hline & & 17 & 52.5 & $55 \cdot 2$ & $61 \cdot 9$ & $67 \cdot 8$ & $75 \cdot 4$ & $86 \cdot 9$ & $98 \cdot 0$ \\
\hline & & 18 & $53 \cdot 1$ & $54 \cdot 9$ & $63 \cdot 7$ & $68 \cdot 8$ & $75 \cdot 7$ & $89 \cdot 9$ & $98 \cdot 6$ \\
\hline \multirow[t]{8}{*}{ Height (m) } & Girls & 15 & $1 \cdot 51$ & $1 \cdot 52$ & $1 \cdot 55$ & $1 \cdot 60$ & $1 \cdot 64$ & 1.68 & $1 \cdot 71$ \\
\hline & & 16 & 1.51 & 1.53 & 1.56 & 1.60 & 1.64 & 1.68 & 1.70 \\
\hline & & 17 & 1.52 & 1.54 & 1.57 & 1.61 & 1.65 & 1.68 & $1 \cdot 70$ \\
\hline & & 18 & $1 \cdot 52$ & 1.53 & 1.56 & $1 \cdot 60$ & 1.65 & 1.69 & 1.70 \\
\hline & Boys & 15 & $1 \cdot 56$ & $1 \cdot 60$ & $1 \cdot 64$ & 1.69 & $1 \cdot 74$ & $1 \cdot 78$ & $1 \cdot 81$ \\
\hline & & 16 & 1.60 & 1.62 & 1.67 & $1 \cdot 72$ & $1 \cdot 76$ & $1 \cdot 80$ & 1.83 \\
\hline & & 17 & 1.62 & 1.63 & 1.68 & $1 \cdot 73$ & $1 \cdot 77$ & $1 \cdot 81$ & 1.83 \\
\hline & & 18 & $1 \cdot 65$ & $1 \cdot 66$ & $1 \cdot 70$ & $1 \cdot 75$ & $1 \cdot 77$ & $1 \cdot 82$ & $1 \cdot 84$ \\
\hline \multirow[t]{8}{*}{ BMI $\left(\mathrm{kg} / \mathrm{m}^{2}\right)$} & Girls & 15 & $18 \cdot 0$ & $18 \cdot 7$ & $20 \cdot 1$ & $22 \cdot 0$ & $24 \cdot 6$ & $27 \cdot 6$ & $29 \cdot 9$ \\
\hline & & 16 & $18 \cdot 1$ & $18 \cdot 8$ & $20 \cdot 2$ & $22 \cdot 1$ & $24 \cdot 4$ & 27.0 & 28.9 \\
\hline & & 17 & $18 \cdot 3$ & $19 \cdot 0$ & $20 \cdot 4$ & $22 \cdot 3$ & $24 \cdot 6$ & $27 \cdot 3$ & $29 \cdot 2$ \\
\hline & & 18 & $18 \cdot 4$ & $19 \cdot 3$ & $20 \cdot 9$ & $23 \cdot 1$ & $25 \cdot 7$ & 28.6 & $30 \cdot 7$ \\
\hline & Boys & 15 & $17 \cdot 6$ & $18 \cdot 3$ & $19 \cdot 7$ & $21 \cdot 6$ & $24 \cdot 2$ & $27 \cdot 5$ & $30 \cdot 3$ \\
\hline & & 16 & $18 \cdot 1$ & $18 \cdot 7$ & $20 \cdot 1$ & 21.9 & $24 \cdot 4$ & $27 \cdot 8$ & 30.3 \\
\hline & & 17 & $18 \cdot 7$ & $19 \cdot 4$ & $20 \cdot 8$ & $22 \cdot 7$ & $25 \cdot 3$ & 28.5 & 31.1 \\
\hline & & 18 & $18 \cdot 9$ & $19 \cdot 6$ & $20 \cdot 9$ & $22 \cdot 7$ & $25 \cdot 2$ & $28 \cdot 6$ & 31.2 \\
\hline \multirow[t]{8}{*}{ WC (cm) } & Girls & 15 & $64 \cdot 1$ & $66 \cdot 8$ & $71 \cdot 8$ & $78 \cdot 1$ & $85 \cdot 2$ & $92 \cdot 6$ & $97 \cdot 5$ \\
\hline & & 16 & 63.9 & $66 \cdot 3$ & 71.9 & $77 \cdot 7$ & $84 \cdot 2$ & $91 \cdot 8$ & $96 \cdot 4$ \\
\hline & & 17 & $65 \cdot 7$ & $68 \cdot 4$ & $73 \cdot 3$ & $79 \cdot 0$ & $86 \cdot 3$ & $93 \cdot 4$ & $98 \cdot 1$ \\
\hline & & 18 & $67 \cdot 0$ & $69 \cdot 9$ & $75 \cdot 2$ & $81 \cdot 8$ & $89 \cdot 1$ & $96 \cdot 5$ & $101 \cdot 3$ \\
\hline & Boys & 15 & $65 \cdot 5$ & $67 \cdot 4$ & $71 \cdot 2$ & $76 \cdot 4$ & $83 \cdot 4$ & $92 \cdot 2$ & 99.5 \\
\hline & & 16 & $67 \cdot 2$ & $69 \cdot 1$ & $72 \cdot 9$ & $78 \cdot 1$ & $84 \cdot 7$ & $92 \cdot 8$ & $99 \cdot 0$ \\
\hline & & 17 & $68 \cdot 7$ & $70 \cdot 6$ & $74 \cdot 1$ & $79 \cdot 2$ & $85 \cdot 7$ & 94.0 & $100 \cdot 8$ \\
\hline & & 18 & $70 \cdot 9$ & $72 \cdot 6$ & $76 \cdot 1$ & 80.9 & $87 \cdot 4$ & $95 \cdot 9$ & $103 \cdot 4$ \\
\hline \multirow[t]{8}{*}{$\mathrm{WH}$ tR } & Girls & 15 & 0.40 & 0.42 & 0.45 & 0.49 & 0.53 & 0.58 & 0.61 \\
\hline & & 16 & 0.40 & 0.41 & 0.44 & 0.48 & 0.52 & 0.56 & 0.59 \\
\hline & & 17 & 0.41 & 0.43 & 0.46 & 0.49 & 0.54 & 0.58 & 0.60 \\
\hline & & 18 & 0.42 & 0.44 & 0.47 & 0.51 & 0.56 & 0.60 & 0.63 \\
\hline & Boys & 15 & 0.39 & 0.40 & 0.42 & 0.45 & 0.49 & 0.54 & 0.59 \\
\hline & & 16 & 0.39 & 0.40 & 0.42 & 0.45 & 0.49 & 0.53 & 0.57 \\
\hline & & 17 & 0.40 & 0.41 & 0.43 & 0.46 & 0.49 & 0.54 & 0.58 \\
\hline & & 18 & 0.41 & 0.42 & 0.44 & 0.46 & 0.50 & 0.55 & 0.60 \\
\hline
\end{tabular}

\section{Statistical analysis}

Decimal age was calculated as the difference between date of birth and date of the data collection. Each age group was categorized by the midpoint of an age range. For example, the group of adolescents categorized as 15 years of age included all adolescents between 14.50 years and $15 \cdot 49$ 

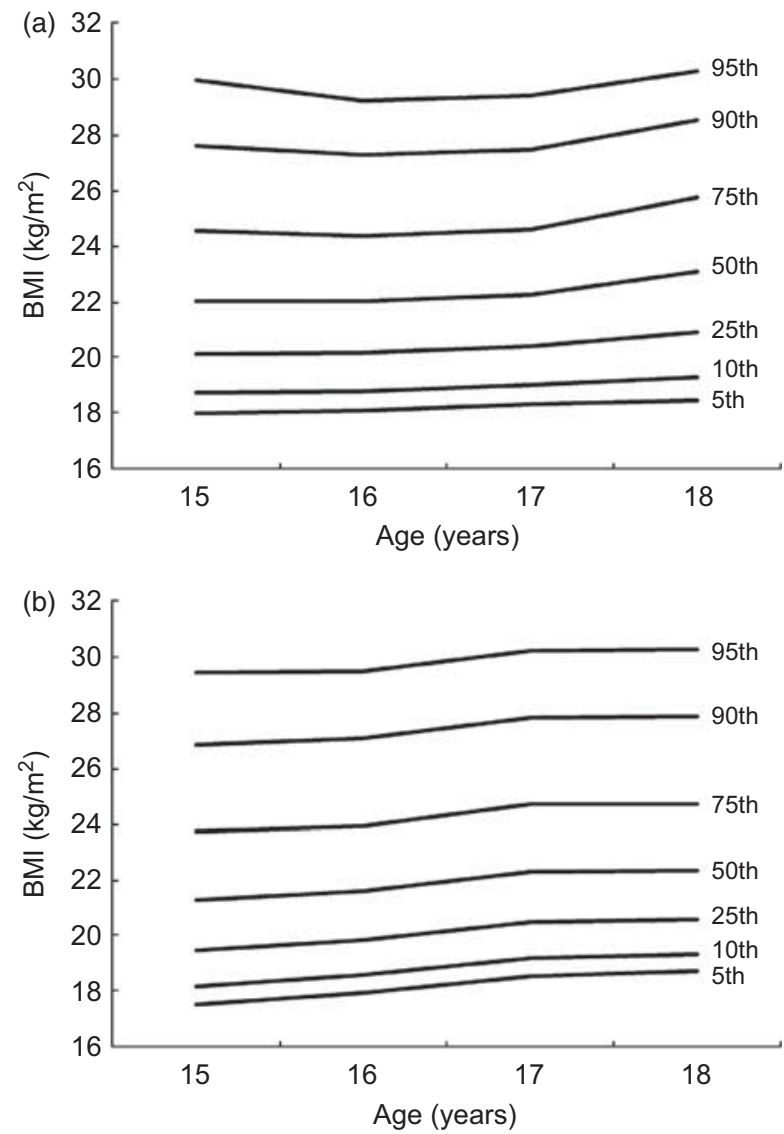

Fig. 1 Sex- and age-specific smoothed BMI percentile curves for adolescents aged 15-18 years, Azores, Portugal: (a) girls; (b) boys

years, and so forth. The 5th, 10th, 25th, 50th, 75th, 85th, 90th and 95 th percentiles were chosen as reference values.

Smoothed percentile curves were estimated using Cole's LMS method ${ }^{(44)}$. The LMS method involves summarizing percentiles at each age based on the power of age-specific Box-Cox power transformations that which are used to normalize the data.

Data management and a descriptive analysis were performed using the SPSS for Windows statistical software package version $17 \cdot 0$ (SPSS Inc., Chicago, IL, USA), whereas the LMS regressions were performed using LMS Pro software (The Institute of Child Health, London, UK). All analyses were weighted to be representative of the Azorean population.

\section{Results}

Descriptive characteristics by age and sex are presented in Table 1 . The prevalence of overweight and obesity was respectively $25 \cdot 3 \%$ and $6 \cdot 3 \%$ in girls and $20 \cdot 1 \%$ and $9 \%$ in boys. Table 2 presents smoothed age- and sex-specific percentile values for weight and height BMI, WC and WHtR. Figures 1, 2 and 3 present the sex- and age-specific smoothed BMI, WC and WHtR percentile curves, respectively.
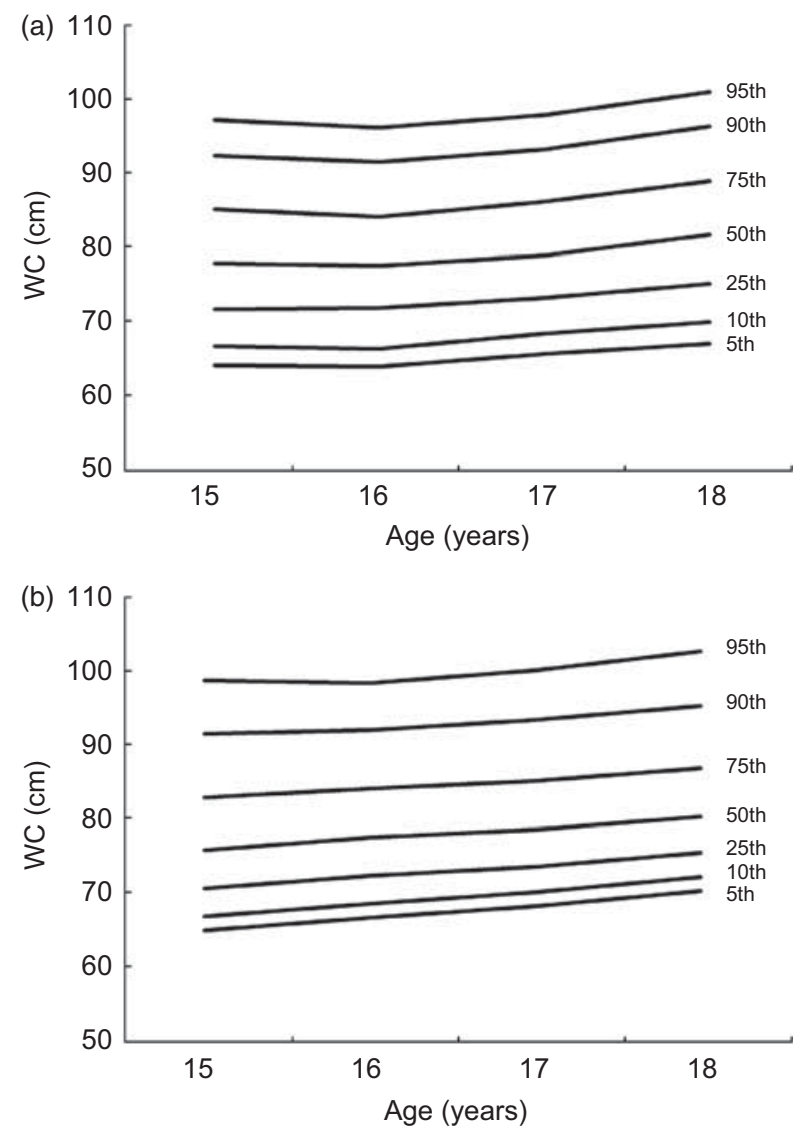

Fig. 2 Sex- and age-specific smoothed waist circumference (WC) percentile curves for adolescents aged 15-18 years, Azores, Portugal: (a) girls; (b) boys

There were some sex differences in the shape of the BMI curves. In girls, the upper percentile values tended to decrease by the age of 16 and 17 years; whereas, in boys, the upper percentiles tended to be flat between 15 and 16 years and then increase until the age of 18 years. In both sexes, the upper percentile values of both WC and WHtR decreased slightly by the age of 16 years and then increased steeply.

Figures 4 and 5 compare the age- and sex-specific 50th and 90th WC percentiles of Azorean girls and boys, respectively, with those of adolescents from other countries. In both sexes the values for the 50th percentile are higher than those reported for adolescents from Great Britain, Hong Kong, Bulgaria, Turkey and China (Han Chinese) and similar to those reported for Kuwait. The 90th percentile of the Azorean girls and boys are also higher than those from Great Britain, Hong Kong, Bulgaria, Turkey and China (Han Chinese) but lower than those reported for Kuwait.

\section{Discussion}

The current study is the first one presenting reference data for BMI, WC and WHtR for Azorean adolescents aged 15-18 years. The current curves may be used as baseline 

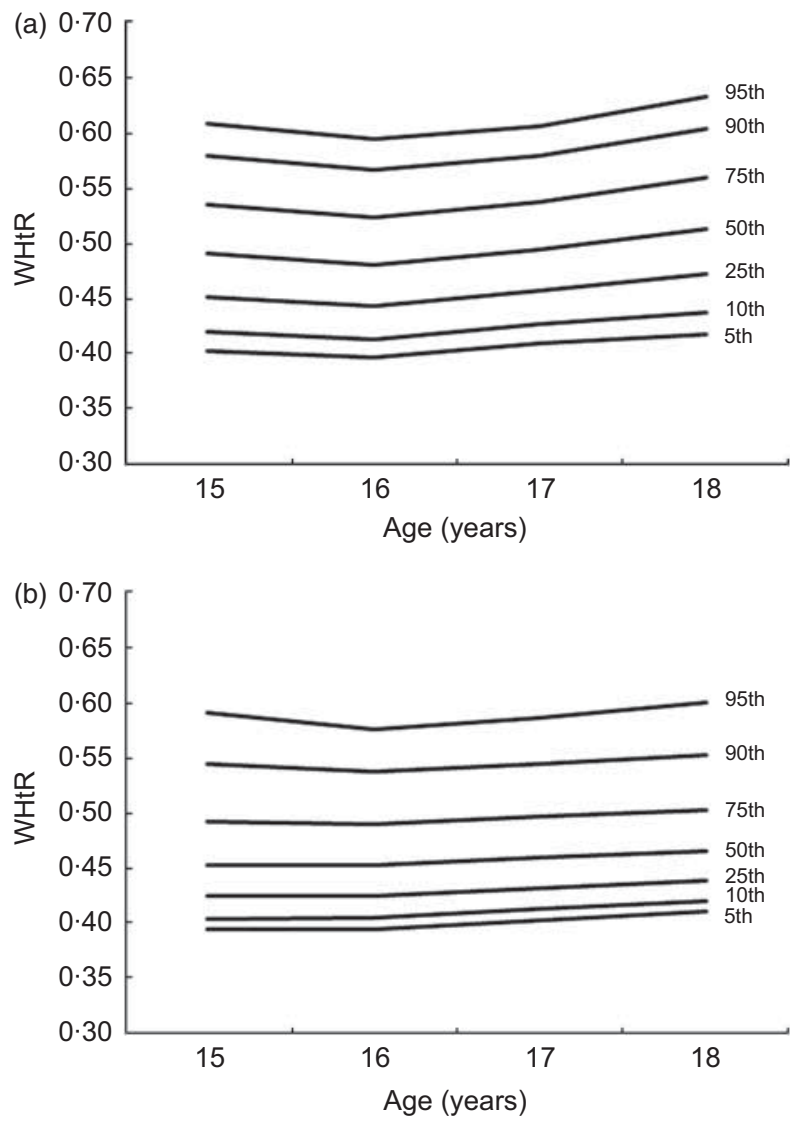

Fig. 3 Sex- and age-specific smoothed waist-to-height ratio (WHtR) percentile curves for adolescents aged 15-18 years, Azores, Portugal: (a) girls; (b) boys

data for long-term obesity surveillance among Azorean adolescents. WC and WHtR curves may also be added to the existing international values.

Comparisons of WC data between different studies require caution since WC may be measured at different sites. Although the literature has demonstrated that WC correlates with percentage fat in the trunk region irrespective of the WC measurement site ${ }^{(45)}$, it is also known that WC mean values $^{(45)}$ and percentile values ${ }^{(33)}$ differ between measurement sites. Since WC can be measured at a variety of different sites, this may also affect the comparisons of WHtR values between studies. Therefore, international agreement about the measurement site in children and adolescents is required in order to facilitate comparisons between percentile values from different populations.

In the present study, we compared the 50th and 90th percentiles only with other studies that also used the same WC measurement protocol, and we found that Azorean adolescents have higher 50th and 90th percentile values than adolescents from other countries, except from Kuwait. Nevertheless, it is important to notice that the British and the Kuwaiti data were collected more than 20 and 12 years ago, respectively, whereas data for other studies were collected in the last 6 years.
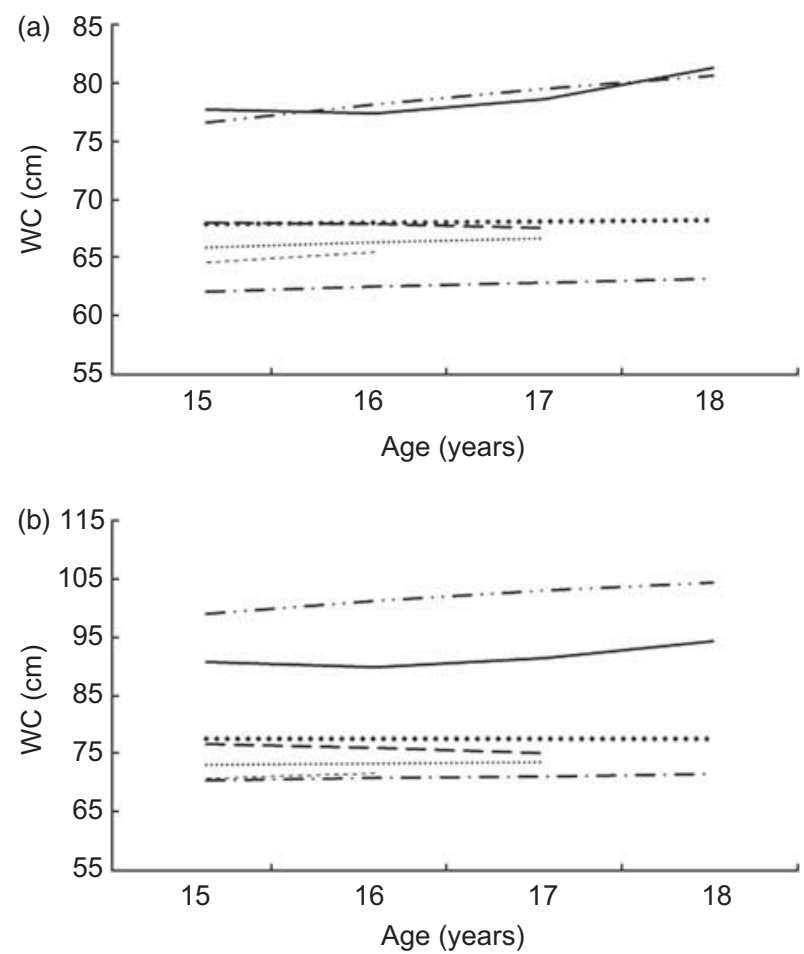

Fig. 4 Comparison of the age-specific waist circumference (WC) percentiles of Azorean girls ( - ) with those of adolescent girls from other countries (......., Turkey; -..-- , Great Britain; - - , China (Han Chinese); ...... Bulgaria; -... , Hong Kong; -.., Kuwait): (a) 50th percentile; (b) 95th percentile
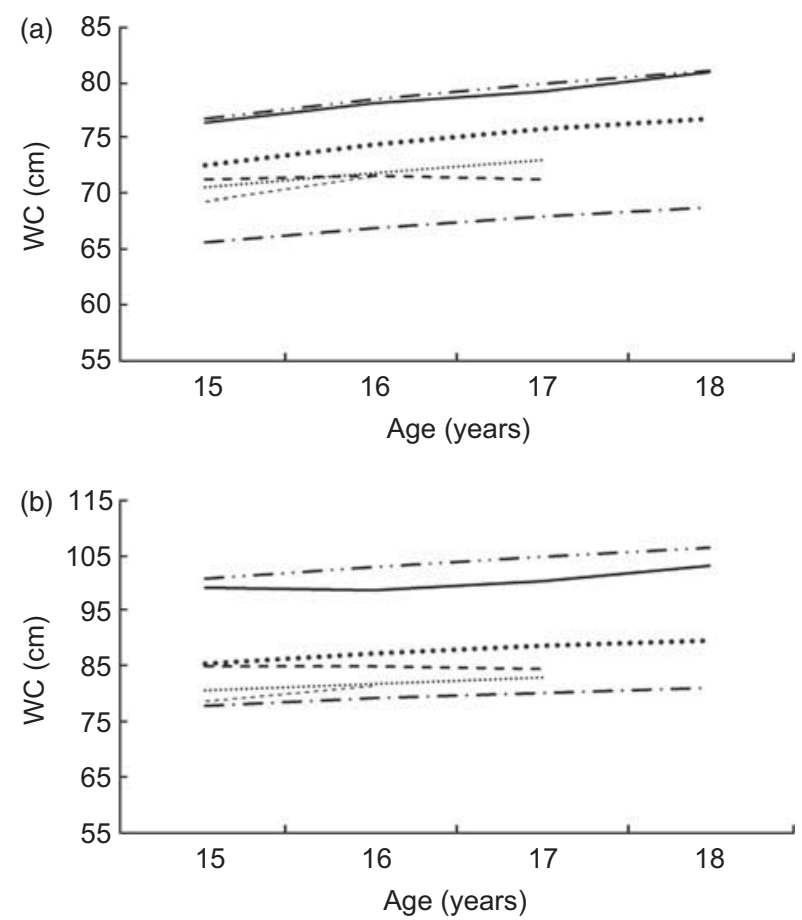

Fig. 5 Comparison of the age-specific waist circumference (WC) percentiles of Azorean boys (-) with those of adolescent boys from other countries (........, Turkey; -.--.- , Great Britain; - - , China (Han Chinese); ...... Bulgaria; - -.. , Hong Kong; - -... Kuwait): (a) 50th percentile; (b) 95th percentile 
The prevalence of overweight and obese children and adolescents has increased in several countries in the last decades $^{(46)}$, and consequently it is possible that WC values may also have changed ${ }^{(47,48)}$. In the UK, for example, the secular increase in WC exceeded that of BMI, suggesting that assessing overweight and obesity trends only by BMI can mask the true obesity-related risk in children and adolescents $^{(48)}$. Indeed, it is known that WC and WHtR are better predictors of CVD risk factors in children than is $\mathrm{BMI}^{(13)}$, and prospective and case-control studies have shown that even within a normal BMI, those with elevated WC are at increased risk of CVD and premature death ${ }^{(49)}$. Nevertheless, Schwandt et al. ${ }^{(50)}$ did not find significant mean differences for WC values in a 10-year trend study of German children.

The high WC percentile values observed in our sample are of concern and may be partially explained by environmental and biological factors or their interaction. Indeed, the Azores is one of the seven 'outermost regions' of the European Union. Those regions are distinguished by their low population density, their considerable distance from mainland Europe, and their considerable structural backwardness for which they have received extra funding from the European Union to improve living conditions and promote economic and social development. The population has European ancestry and the economic activity is mainly based on tourism, fishing and agriculture. Azores has some unique social and geographical features and an urban design that differs from the mainland. All of the islands have volcanic origins and numerous landscapes with virgin forest and green fields. Most of the urban areas are small and located on the coast. Unfortunately, there are no percentile curves for BMI, WC or WHtR available for Portuguese children and adolescents, and therefore no comparisons between Azorean youth and mainland Portuguese youth can be done. In this context, future studies observing obesity trends in children and adolescents should also consider WC as well as WHtR as screening instruments.

\section{Conclusions}

The reference curves presented in the current study provide baseline data for the long-term surveillance of Azorean children and adolescents, as well as for national and international comparisons.

\section{Acknowledgments}

The present study was supported by grants from the Fundação para a Ciência e Tecnologia - Ministério da Ciência, Tecnologia e Ensino Superior (FCT-MCTES; BD/ 44422/2008, BPD/65180/2009, BSAB/1025/2010 and PTDC/ DES/098309/2008); by the Azorean Government; and by the Spanish Ministry of Science and Innovation (RYC-201005957). There are no conflicts of interest. R.S., P.M. and J.M. conceived the study design, performed statistical analyses and wrote the paper; S.V., J.R.R., C.M., L.S.-M., L.L. and M.J.C.-S., wrote the paper; A.I.M., A.O.-T., P.C.S. and S.A. collected the data and performed statistical analyses. The authors are grateful to all teachers and technical staff who were involved in data collection procedures.

\section{References}

1. Wang Y \& Lobstein T (2006) Worldwide trends in childhood overweight and obesity. Int J Pediatr Obes 1, 11-25.

2. Sardinha LB, Santos R, Vale S et al. (2010) Prevalence of overweight and obesity among Portuguese youth: a study in a representative sample of 10-18-year-old children and adolescents. Int J Pediatr Obes 6, e124-e128.

3. Centers for Disease Control and Prevention (2000). CDC growth charts: United States. http://www.cdc.gov/growth charts (accessed February 2009).

4. Cole TJ, Bellizzi MC, Flegal KM et al. (2000) Establishing a standard definition for child overweight and obesity worldwide: international survey. BMJ 320, 1240-1243.

5. World Health Organization (2007). Growth reference data for 5-19 years. http://www.who.int/growthref/who2007_ bmi_for_age/en/ (accessed May 2009).

6. Brambilla P, Bedogni G, Moreno LA et al. (2006) Crossvalidation of anthropometry against magnetic resonance imaging for the assessment of visceral and subcutaneous adipose tissue in children. Int J Obes (Lond) 30, 23-30.

7. Cattaneo A, Monasta L, Stamatakis E et al. (2010) Overweight and obesity in infants and pre-school children in the European Union: a review of existing data. Obes Rev 11, 389-398.

8. Clasey JL, Bouchard C, Teates CD et al. (1999) The use of anthropometric and dual-energy X-ray absorptiometry (DXA) measures to estimate total abdominal and abdominal visceral fat in men and women. Obes Res 7, 256-264.

9. Pouliot MC, Despres JP, Lemieux S et al. (1994) Waist circumference and abdominal sagittal diameter: best simple anthropometric indexes of abdominal visceral adipose tissue accumulation and related cardiovascular risk in men and women. Am J Cardiol 73, 460-468.

10. Schreiner PJ, Terry JG, Evans GW et al. (1996) Sex-specific associations of magnetic resonance imaging-derived intraabdominal and subcutaneous fat areas with conventional anthropometric indices. The Atherosclerosis Risk in Communities Study. Am J Epidemiol 144, 335-345.

11. Soto Gonzalez A, Bellido D, Buno MM et al. (2007) Predictors of the metabolic syndrome and correlation with computed axial tomography. Nutrition 23, 36-45.

12. Freedman DS, Serdula MK, Srinivasan SR et al. (1999) Relation of circumferences and skinfold thicknesses to lipid and insulin concentrations in children and adolescents: the Bogalusa Heart Study. Am J Clin Nutr 69, 308-317.

13. Savva SC, Tornaritis M, Savva ME et al. (2000) Waist circumference and waist-to-height ratio are better predictors of cardiovascular disease risk factors in children than body mass index. Int J Obes Relat Metab Disord 24, 1453-1458.

14. Moreno LA, Pineda I, Rodriguez G et al. (2002) Waist circumference for the screening of the metabolic syndrome in children. Acta Paediatr 91, 1307-1312.

15. Ruiz JR, Rizzo NS, Hurtig-Wennlof A et al. (2006) Relations of total physical activity and intensity to fitness and fatness in children: the European Youth Heart Study. Am J Clin Nutr 84, 299-303.

16. Zimmet P, Alberti KG, Kaufman F et al. (2007) The metabolic syndrome in children and adolescents - an IDF consensus report. Pediatr Diabetes 8, 299-306. 
17. Weiss R, Dufour S, Taksali SE et al. (2003) Prediabetes in obese youth: a syndrome of impaired glucose tolerance, severe insulin resistance, and altered myocellular and abdominal fat partitioning. Lancet 362, 951-957.

18. Daniels SR, Khoury PR \& Morrison JA (2000) Utility of different measures of body fat distribution in children and adolescents. Am J Epidemiol 152, 1179-1184.

19. Kelishadi R, Gheiratmand R, Ardalan G et al. (2007) Association of anthropometric indices with cardiovascular disease risk factors among children and adolescents: CASPIAN Study. Int J Cardiol 117, 340-348.

20. Maffeis C, Pietrobelli A, Grezzani A et al. (2001) Waist circumference and cardiovascular risk factors in prepubertal children. Obes Res 9, 179-187.

21. Lee S, Bacha F, Gungor N et al. (2006) Waist circumference is an independent predictor of insulin resistance in black and white youths. J Pediatr 148, 188-194.

22. Katzmarzyk PT (2004) Waist circumference percentiles for Canadian youth 11-18y of age. Eur J Clin Nutr 58, 1011-1015.

23. McCarthy HD, Jarrett KV \& Crawley HF (2001) The development of waist circumference percentiles in British children aged 5.0-16.9 y. Eur J Clin Nutr 55, 902-907.

24. Moreno LA, Fleta J, Mur L et al. (1999) Waist circumference values in Spanish children - gender related differences. Eur J Clin Nutr 53, 429-433.

25. Hatipoglu N, Ozturk A, Mazicioglu MM et al. (2008) Waist circumference percentiles for 7- to 17-year-old Turkish children and adolescents. Eur J Pediatr 167, 383-389.

26. Yan W, Yao H, Dai J et al. (2008) Waist circumference cutoff points in school-aged Chinese Han and Uygur children. Obesity (Silver Spring) 16, 1687-1692.

27. Savva SC, Kourides Y, Tornaritis M et al. (2001) Reference growth curves for cypriot children 6 to 17 years of age. Obes Res 9, 754-762.

28. Fernandez JR, Redden DT, Pietrobelli A et al. (2004) Waist circumference percentiles in nationally representative samples of African-American, European-American, and Mexican-American children and adolescents. J Pediatr 145, 439-444.

29. Sung RY, So HK, Choi KC et al. (2008) Waist circumference and waist-to-height ratio of Hong Kong Chinese children. BMC Public Health 8, 324.

30. Fredriks AM, van Buuren S, Fekkes M et al. (2005) Are age references for waist circumference, hip circumference and waist-hip ratio in Dutch children useful in clinical practice? Eur I Pediatr 164, 216-222.

31. Eisenmann JC (2005) Waist circumference percentiles for 7- to 15-year-old Australian children. Acta Paediatr 94, 1182-1185.

32. Kelishadi R, Gouya MM, Ardalan G et al. (2007) First reference curves of waist and hip circumferences in an Asian population of youths: CASPIAN study. J Trop Pediatr 53, 158-1564.

33. Inokuchi M, Matsuo N, Anzo M et al. (2007) Age-dependent percentile for waist circumference for Japanese children based on the 1992-1994 cross-sectional national survey data. Eur J Pediatr 166, 655-661.
34. Xiong F, Garnett SP, Cowell CT et al. (2011) Waist circumference and waist-to-height ratio in Han Chinese children living in Chongqing, south-west China. Public Health Nutr 14, 20-26.

35. Jackson RT, Al Hamad N, Prakash P et al. (2011) Waist circumference percentiles for Kuwaiti children and adolescents. Public Health Nutr 14, 70-76.

36. Zannolli R \& Morgese G (1996) Waist percentiles: a simple test for atherogenic disease? Acta Paediatr 85, 1368-1369.

37. Ashwell M, Cole TJ \& Dixon AK (1996) Ratio of waist circumference to height is strong predictor of intraabdominal fat. BMJ 313, 559-560.

38. Ashwell M \& Hsieh SD (2005) Six reasons why the waist-toheight ratio is a rapid and effective global indicator for health risks of obesity and how its use could simplify the international public health message on obesity. Int J Food Sci Nutr 56, 303-307.

39. World Health Organization (2000) Obesity: Preventing and Managing the Global Epidemic. WHO Technical Report Series no. 894. Geneva: WHO.

40. Browning LM, Hsieh SD \& Ashwell M (2010) A systematic review of waist-to-height ratio as a screening tool for the prediction of cardiovascular disease and diabetes: 0.5 could be a suitable global boundary value. Nutr Res Rev 23, 247-269.

41. Instituto Nacional de Estatística (2003) Instituto Nacional de Estatística Estimativas da População Residente, segundo GrandesGrupos Etários e Sexo, em 31/12/2003 [National Institute of Statistics. Estimation of the Resident Population, According to Age and Gender, in 31/12/2003]. Lisbon: INE; available at http://www.ine.pt/

42. World Medical Association (1989) World Medical Association Handbook of Declarations. Farney Voltaire: WMA.

43. Lohman TG, Roche AF \& Martorell R (1988 (editors) Anthropometric Standardization Reference Manual. Champaign, IL: Human Kinetics Books.

44. Cole TJ \& Green PJ (1992) Smoothing reference centile curves: the LMS method and penalized likelihood. Stat Med 11, 1305-1319.

45. Wang J, Thornton JC, Bari S et al. (2003) Comparisons of waist circumferences measured at 4 sites. Am J Clin Nutr 77, 379-384.

46. Lobstein T \& Frelut ML (2003) Prevalence of overweight among children in Europe. Obes Rev 4, 195-200.

47. Li C, Ford ES, Mokdad AH et al. (2006) Recent trends in waist circumference and waist-height ratio among US children and adolescents. Pediatrics 118, e1390-e1398.

48. McCarthy HD, Jarrett KV, Emmett PM et al. (2005) Trends in waist circumferences in young British children: a comparative study. Int J Obes (Lond) 29, 157-162.

49. Lear SA, James PT, Ko GT et al. (2010) Appropriateness of waist circumference and waist-to-hip ratio cutoffs for different ethnic groups. Eur J Clin Nutr 64, 42-61.

50. Schwandt P, Kelishadi R \& Haas GM (2008) First reference curves of waist circumference for German children in comparison to international values: the PEP Family Heart Study. World J Pediatr 4, 259-266. 